\title{
Report
}

\section{Hidden Suffering - Unemployed Voice Concerns About Transmission of Their Health Data to the Job Centre}

\author{
Hummernbrum Sabine \\ Department of Environmental Health, Medical University of Vienna, Vienna, Austria \\ Email address: \\ office@oeget.org
}

\section{To cite this article:}

Hummernbrum Sabine. Hidden Suffering - Unemployed Voice Concerns About Transmission of Their Health Data to the Job Centre. European Journal of Preventive Medicine. Vol. 7, No. 1, 2019, pp. 29-31. doi: 10.11648/j.ejpm.20190701.16

Received: January 13, 2019; Accepted: March 4, 2019; Published: March 28, 2019

\begin{abstract}
There are only few clinical studies that address the effects of unemployment on somatic health. Only under certain, particularly strict criteria, are unemployed adults to be included in studies as they are subjected to special attention by ethics committees given their status as "vulnerable subjects". Our original goal was to obtain data on the risk factor unemployment via a pseudonymized survey and a fitness test (spirometry or ergometry). A problem we faced was that majority of participants were very concerned about answering questions on their state of health. Even with a modified study design, an entirely anonymous survey, the concerns remained. Subsequent expert interviews showed that unemployed people, as patients, even have reservations when talking about their health to their doctors. They fear that the health data stored in the social insurance data set was accessible to the AMS. This behavior of avoidance could affect the health care of this demographic.
\end{abstract}

Keywords: Unemployment, Data Protection, Poverty, Ethic, Public Health, Good Clinical Practice

\section{Introduction}

While unemployment was only a problem for fringe groups a few decades ago, almost everyone today experiences a period of unemployment at some point in their professional life. [1, 2] Jobseekers are often at risk of poverty [2, 3] and are also mostly dependent on bridging institutions, in Austria the Public Employment Service, (short form AMS) and in some cases, specifically in Vienna the Social Department (MA 40). Medical research involving unemployed people is subject to particularly strict conditions in Austria. This group of people is considered to be "vulnerable" in accordance to "Good Clinical Practice". Therefore various ethics committees are vigilant both nationally and internationally that this support-depended group is not to be lured into study-related therapies and examinations with - in comparison to the aid provided by the AMS - high compensations. [4-7]

\section{Methods}

\subsection{Methods of the Primary Study}

To study the effects of unemployment on somatic health, we invited more than 600 adults in Vienna registered unemployed to participate in a study conducted by the Department of Environmental Health at Medical University of Vienna (MUW). The study design and the study protocol were submitted to the Ethics Committee of the Medical University of Vienna. The Ethics Committee proceeded to issue an ethics vote for a period of one year with strict regulations regarding data protection and compensation. All participants were explicitly informed on the terms of participation that no personal data is passed on to the AMS, the MA 40 or the social insurance. Every participant was provided with sufficient detail on data protection and the overall conduct of the study in the terms of participation as well as in the declaration of consent, which had to be read and signed by each participant before participation. Participation in the study was completely voluntary and all collected data was pseudonymised. The core of this primary study consisted of a questionnaire on the 
subject's health and socio-economic situation in addition a free fitness test with spirometry and ergometry was offered to also obtain objective data from a subsample of the study population. Participants were able to decide whether they would either just fill out the questionnaire or additionally agree on a separate appointment for spirometry and ergometry. In 2 Viennese social markets and 2 Viennese AMS counselling centres (regional offices) potentially interested individuals were invited to participate by posters, leaflets and active advertisement by discussion. None of the participants were "assigned" to us by the AMS (no AMS staff member was involved in the study) and the potential subjects were exclusively supervised by employees of the MUW whilst the AMS received no information about their participation. The selection of potential subjects was purely random and standardized in the sense that every adult who was in the room and who was not part of the AMS staff was invited to participate in the study. Already in the feasibility study, a pure questionnaire study, preceding this study the participants expressed concerns about data security.

\subsection{Detection Methods in Respect of Participants Concerns}

Despite a vote of ethics and extensive information regarding patient and data protection, the suspicion that personal data was covertly collected at the order of the AMS could not be alleviated. Many subjects felt unduly "researched" and were convinced that the questionnaires were passed on to the AMS and feared negative effects on benefits they were receiving. In order to refute this suspicion, we have decided to, at least for the questionnaire, refrain from collecting any personal data. The participants were allowed to abstain from signing the "informed consent" and instead provide either a telephone number, an e-mail address or just a first name or alias. Even in this adapted setting the participants did not feel save and comfortable. To investigate this problem in more depth, we asked all participants, who refused to sign the consent form, about their concerns. Taking into account that our participants were likely to refuse all paperwork, especially a further consent form, we waived paper questionnaires and consent forms and started with a more client friendly interview style based on free interview and open conversation. All answers were later on written down by the interviewers and discussed. In this setting it was only possible to obtain data sufficient for a first general analysis. We are not able to provide results in exact percent value.

\section{Results}

Cave: In this paper, we will not discuss the results of the primary study. In the following we focus exclusively on our, as we think, striking cofindings. Two-thirds of the respondents refused to participate, with the majority clearly stating "fear of data transfer to the AMS" as the reason for the refusal. Other reasons such as "I don't have my glasses with me", "do not speak German", "no time" were mentioned, but did not correspond to the real situation. The subjects were offered to have the questions read to them and to have them translated. It should be noted that the people would have actually had time because they were waiting on counselling appointments for which they also should appear with glasses, as necessary, and were then even observed while reading without them contrary to their previous statements. Attempts to assure the potential subjects that they could complete the questionnaire without having to provide any contact data could not alleviate their fears. Some respondents even stated, without being asked, that the questionnaires in connection with their appointment details could be used to draw conclusions on them (the AMS is aware of which people are in the AMS on which days), although on this day approx. 300 people visited the AMS. People also voiced concerns about recognition of their handwriting. Interestingly, this problem was not limited to the AMS. Even those participants recruited as anonymous customers in social markets happily obliged to fill out the questionnaire, but often provided incorrect contact information, wrote their names illegibly, also voiced privacy concerns. For the clinical part of the study, we had to insist that we would be provided with the full name and that we would be presented a photo ID for legal reasons. Interest in participation was correspondingly low. We later discussed these results in expert panels consisting of experienced adult educators and self-help groups for the unemployed. It turns out that many unemployed people even have concerns about opening up about their physical and mental suffering with their general practitioner. These patients express concern that mental health conditions, acute or chronic illnesses, unhealthy lifestyles (smoking, alcohol consumption), or even disposition to certain diseases (risk groups) could be stored in their social security record and subsequently be viewed by the AMS. According to the opinion of the jobseekers asked, such data could serve as a basis for decision-making, restricting or suspending aid, or at a later stage this information could even negatively affect their care by AMS employees: upon allocation of often scarce participation slots in expensive and much sought-after trainings it could then be argued internally: "too sick for training, training does not make sense".

\section{Discussion}

We have tried to avoid any recruitment bias for our study. Given our narrow time window and with the limited number of people available to us, we tried to talk to as many people on site as possible. We would have liked to continue our survey in or at least in the entrance area of work training centres, which we were not allowed to by the training institutes. Asking people in public places to participate did not make sense as it is not possible to determine with certainty whether a person is unemployed or not. With a total of 602 respondents, we feel confident that we have contacted a sufficient number of unemployed Persons. Although we cannot completely exclude any participation bias and therefore our sample is not fully representative for unemployed Austrians, we wanted to publish these results to encourage large-scale studies on this topic. We extensively searched the present literature on the topic but could not find any publications dealing with our 
problem. This is why our amount of citations and references is meager only few served as background information. Our findings are limited due to restrictions in time, limitations in the system of unemployment service itself and general data protection. We tried hard to give a complete picture of the present situation and hope to encourage more scientists to focus on ethical issues referring to unemployment and health.

\section{Conclusions}

The concerns of the unemployed to disclose their state of health, their physical and mental health, be it in medical studies, when visiting the family doctor or to the AMS consultants, lead to wrong decision-making basis in science and politics. If this problem occurs to such an extent in the demographic of people seeking employment as we have determined it to, this would lead to the conclusion that, due to the entanglement of social insurance and service provider AMS, a not inconsiderable part of the adult population is subjectively not able to access adequate medical care to the same extent as other groups in society. Preventive examinations could be postponed, anamnesis could not be completed and harmful behaviour such as alcohol consumption would remain concealed. This could negatively affect the health care of this population.

\section{References}

[1] Wanberg CR. The individual experience of unemployment. Annu Rev Psychol 2012; 63: 369-96.

[2] oeget. Österreichische Gesellschaft für EZA und Technologie. AMS- BO-Trainerbefragung 2015.

[3] Brown DW, Balluz LS, Ford ES, Giles WH, Strine TW, Moriarty DG, et al. Associations between short- and long-term unemployment and frequent mental distress among a national sample of men and women. J OccupEnvironMed 2003; 45(11): $1159-66$.

[4] Robert E. Goodi. Protecting the vulnerable: A re Analysis of our social responsibility.(London, Chicago). The University of Chicago Press 1985; 110.

[5] Bradshaw CP, Rebok GW, Zablotsky B, Laflair LN, Mendelson T, Eaton WW. Models of stress and adapting to risk: a life course, developmental perspective. In: Eaton WW, editor. Public mental health. New York (NY): Oxford University Press; 2012. p. 269-302.

[6] C von Dewitz, FC Luft, C Pestalozza. Ethikkommissionen in der medizinischen Forschung. Gutachten im Auftrag der Bundesrepublik Deutschland für die Enquête-Kommission "Ethik und Recht der modernen Medizin" des Deutschen Bundestages, 2004.

[7] Erwin Deutsch, Andreas Spickhoff. Medizinrecht, Arztrecht, Arzneimittelrecht, Medizinproduktrecht und Transfusionsrecht Springer-Verlag 2014; S. 921-2. 